Jessica Gard Timmerfors*, Torbjörn Sjölund and Leif J. Jönsson

\title{
New drum-chipping technology for a more uniform size distribution of wood chips
}

https://doi.org/10.1515/hf-2018-0279

Received November 29, 2018; accepted March 6, 2019; previously published online April 8, 2019

\begin{abstract}
Wood chips from a novel type of drum chipper were compared to wood chips from a conventional disc chipper in an evaluation based on demonstration-scale and industrial-scale machinery. The evaluation was performed as the wood chippers were used as production machines in a kraft pulp mill using softwood. The average bulk density of the wood chips from the disc chipper and the drum chipper was similar and within the range of $138-140 \mathrm{~kg} / \mathrm{m}^{3}$. The size distribution of the wood chips was investigated using a conventional screening method, and by using an automatized image-analysis system based on laser scanning. The average length was set to be the same, but the wood chips from the drum chipper had a more uniform length. The average thickness was similar, but the drum chipper generated slightly more thinner wood chips. Compared to the disc chipper and using the screening method, the drum chipper generated a similar fraction of oversized and overthick wood chips, 51\% more large accept chips, $11 \%$ more total accept chips, and $74 \%$ less pin chips and fines. Image analysis resulted in similar data. The results indicate that drum chippers warrant further attention as an alternative to conventional industrial-scale disc chippers.
\end{abstract}

Keywords: bulk density, disc chipper, drum chipper, kraft pulping, size distribution, wood chips

\section{Introduction}

Wood chipping is an essential step in most forest-industrial processes. With regard to wood chipping for chemical pulping, the aim is to produce high yields of wood chips of uniform size that efficiently can be impregnated with

\footnotetext{
*Corresponding author: Jessica Gard Timmerfors, Department of Chemistry, Umeå University, SE-901 87 Umeå, Sweden, e-mail: jessica.gard.timmerfors@umu.se

Torbjörn Sjölund: More Research Örnsköldsvik AB, Box 70, SE-891 22 Örnsköldsvik, Sweden

Leif J. Jönsson: Department of Chemistry, Umeå University, SE-901 87 Umeå, Sweden
}

the cooking liquid and processed in the digester without problems. Wood chip quality affects processability, yield, and product quality.

Size fractionation of wood chips gives oversized chips, overthick chips, accept chips (large and small), pin chips, and fines (Brännvall 2009). Oversized and overthick wood chips are further processed before being used for production of pulp (Määttänen and Tikka 2008), whereas pin chips and fines to a large extent represent a loss. Even when removed, fines can cause dust problems and increased fire risk.

Although pulping processes differ in sensitivity to uneven distribution of chemicals during impregnation and uneven temperatures (Rydholm 1965), all fibers in the wood need to get their share of the chemicals and the heat during the cooking process. Therefore, many recent studies have addressed the impregnation of wood chips in kraft pulping, the most common chemical pulping method (Malkov et al. 2002; Malkov et al. 2003; Wedin et al. 2010; Brännvall and Bäckström 2016; Tavast and Brännvall 2017; Brännvall and Reimann 2018). Poor wood chip quality can result in more shives in the pulp, or even in digester shutdown. As wood chipping is an energy-intensive operation and as forest-industrial processes are highly yield dependent, it would be advantageous to increase the fraction of accept chips while keeping the fraction of pin chips and fines to a minimum. High wood chip quality is typically characterized by a low fraction of overthick chips, a low fraction of pin chips, a low fraction of undersized chips (fines), and uniform wood chip density (Hartler and Stade 1977; Uhmeier 1995; Hartler 1996).

The wood chip quality will be affected by both the feedstock characteristics and the chipping process. Conventional industrial wood chippers used for pulp production are disc chippers that are an integrated part of the pulp mill. For wood fuel production, small and sometimes mobile disc chippers or drum chippers are used (Nati et al. 2014; Pichler et al. 2018). With regard to pulp production, an inherent problem with disc chippers is the uneven velocity across the disc (Figure 1a), which will contribute to the heterogeneity of wood chips. Industrial development proceeds toward larger mills with larger wood chippers. However, a larger disc size will accentuate the problem with heterogeneity due to increased speed gradient over the disc (Hartler 1996; Brännvall 2009; Abdallah et al. 2011). 
a
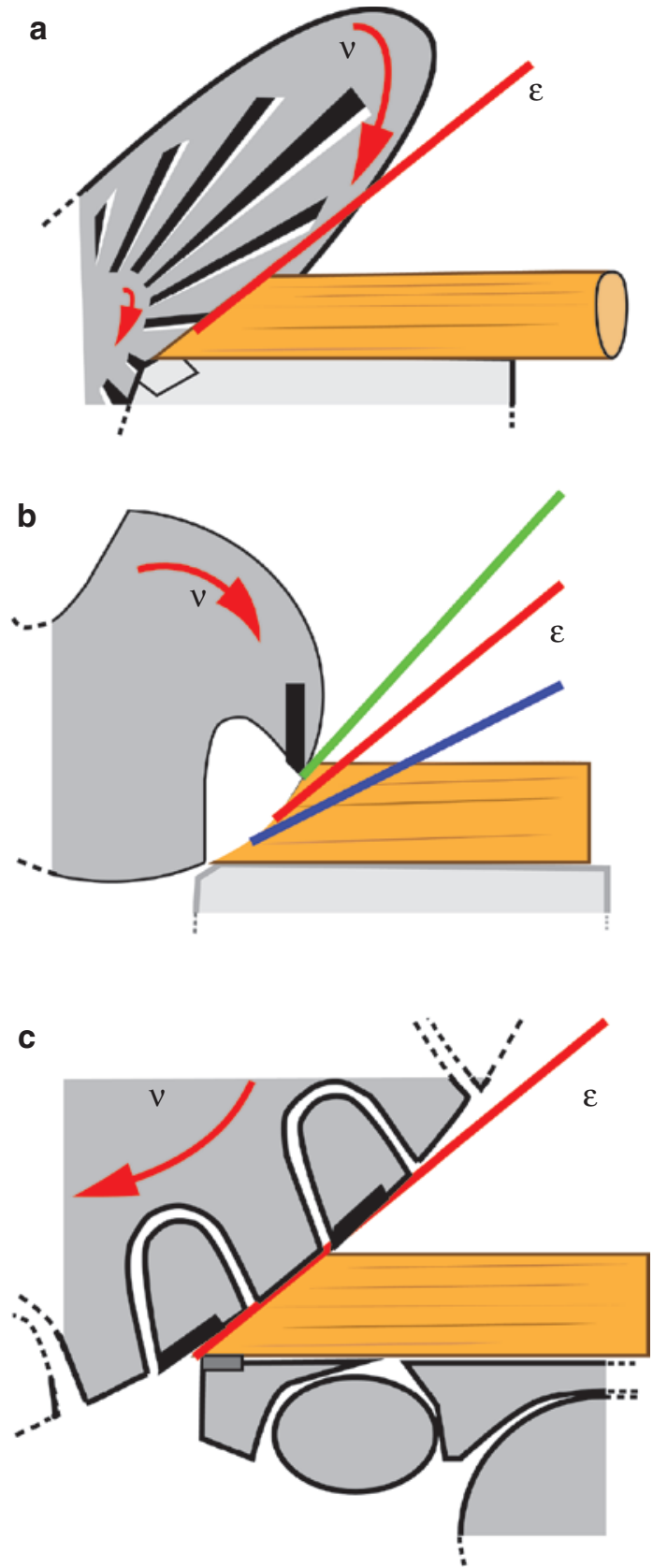

Figure 1: Simplified scheme of wood chippers.

(a) A disc chipper (three-dimensional to show the change in velocity, $v$, over the knives), (b) a conventional drum chipper, and (c) the novel drum chipper. The cutting/spout angle $\varepsilon$ (the angle between the cutting direction and the fiber direction) is constant for a disc chipper (a), highly variable for a conventional drum chipper (b), and almost constant for the novel drum chipper (c). This is indicated by red lines (desired cutting angles), a blue line (smaller cutting angle), and a green line (larger cutting angle).

An inherent advantage with drum chippers is that the velocity of the knives is the same across the drum (Figure 1b). Therefore, theoretically, drum chippers should produce more homogeneous wood chips than disc chippers. However, it is not only variable velocity that causes heterogeneity. Conventional drum chippers with small drums (Figure $1 \mathrm{~b}$ ) have a variable cutting angle (spout angle) $(\varepsilon)$ and a complementary angle $(\lambda)$ (Figure 2). The cutting angle will influence the size distribution of wood chips. An increased cutting angle will increase the fraction of small-sized chips, the chip thickness (at constant average length), and the bulk density. A decreased cutting angle is beneficial with regard to chip size homogeneity, but decreases the bulk density of the wood chips. If the cutting angle is increased from slightly more than $30^{\circ}$ (the conventional value) to $40^{\circ}$ or even to $50^{\circ}$, the cracking of the wood chips will increase and the fraction of accept chips will decrease (as the fractions of both overthick chips and pin chips will increase) (Hartler 1962; Hartler 1996; Hellström et al. 2011). The average chip thickness increases almost linearly with increased chip length, as determined by the complementary angle. Changes in this angle are due to changes in either the cutting angle or the sharpness angle ( $\beta$ ) (Hartler 1962; Hartler and Stade 1977; Twaddle 1997).

A problem related to the packing of wood chips is the degree of curviness, which affects the bulk density. Wood chips are expected to be flat, and having too many curved chips can lead to bridging and, in serious cases, complete plugging of the digester (Hartler and Stade 1977). Variations in bulk density can lead to overuse of chemicals, lower production capacity in the digester, and lower production rate (Edberg et al. 1973; Hartler 1996).

A novel type of drum chipper that supposedly combines the best properties of conventional drum and

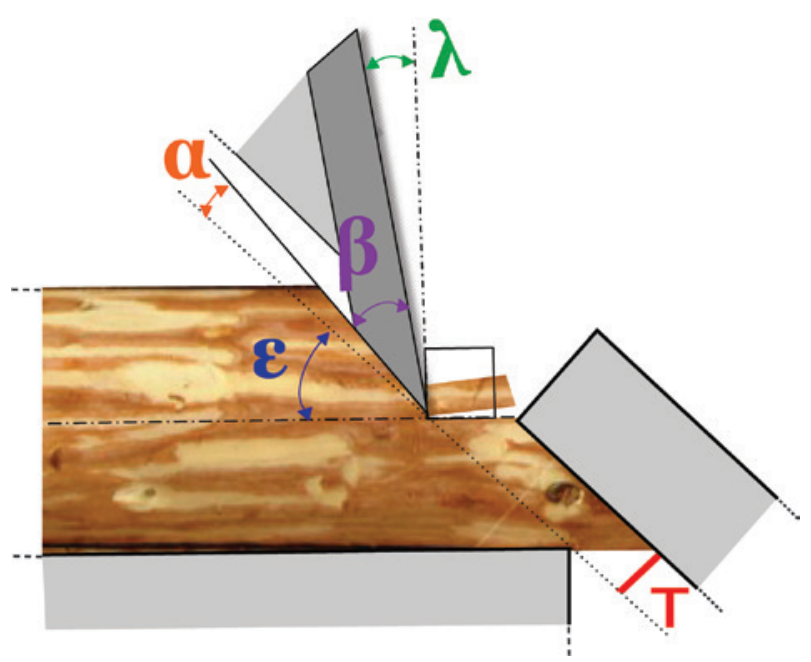

Figure 2: Definitions of angles: $\varepsilon$ (cutting/spout angle), $\alpha$ (clearance/pulling angle), $\beta$ (sharpness $/ \mathrm{knife}$ angle), and $\lambda$ (complementary angle) $\left(\varepsilon+\alpha+\beta+\lambda=90^{\circ}\right)$.

$\mathrm{T}$ dimension refers to the clearance between the wear plate and the knives. 
disc chippers has been developed (Figure 1c). As it is a drum chipper, there is no difference in velocity over the knife. It has similar knife-to-anvil distance and similar knife-to-wear-plate clearance ( $\mathrm{T}$ dimension, Figure 2) as conventional disc chippers, which is possible due to specially designed wood chip channels (Figure 1c). These wood chip channels represent a difference compared to conventional drum chippers (Figure 1b). The function of the channels is to guide the wood chips away from the drum. The size of the drum is important for making wood chips that are uniform in size and have the desired shape. The diameter of the drum ought to be at least 10 times larger than the maximum diameter of the wood logs. Due to larger variability in $\mathrm{T}$ dimension, smaller drum chippers will produce more curved wood chips that are less uniform with regard to length and thickness. The new drum chipper will exhibit only small variability with regard to the cutting angle (Figures $1 \mathrm{c}$ and 2). At least in theory, the small variability in cutting angle of the new drum chipper would not have any clear effect on the uniformity of the wood chips. However, that still needs to be verified in practice.

In this study, a demonstration-scale version of the new drum chipper (Figure 1c) was tested at a kraft pulp mill to investigate the effects on wood chip dimensions and bulk density. The wood chips from the new drum chipper were compared to wood chips from a conventional industrial-sized disc chipper (Figure 1a) used in the mill. that they were produced using a mix of wood logs of different diameters, moisture contents, and ages. The wood log diameter was 50$600 \mathrm{~mm}$, whereas the average diameter was $150 \mathrm{~mm}$. The wear of the knives depends primarily on the time period since the last knife change. To minimize the effects of that on the results, the wood chip samples used in this study were taken both before and after change of knives, as well as in between.

Two to three times per day, wood chip samples were taken from the conveyer belt directly after the drum or disc chipper. Each wood chip sample consisted of 40-60 l, which were collected with a brush from a 1-2 $\mathrm{m}$ portion of the stopped conveyer belt to get representative samples. The wood chip samples were mixed according to the SCAN-CM (Scandinavian Pulp, Paper and Board Testing Committee's series of test methods for chemical and mechanical pulps and wood chips) 41:94 procedure before fractions used for analysis were withdrawn.

Analysis of bulk density: Bulk density was measured using the SCAN-CM 46:92 method. Determination of dry weight was performed according to the directions in the SCAN-CM 46:92 method (i.e. using the SCAN-CM 39:94 method).

Analysis of size distribution: Manual analyses of wood chips were performed using the standard method SCAN-CM 40:01 (size distribution). Image analysis of wood chips was performed using a ScanChip analyzer (PulpEye, Örnsköldsvik, Sweden) located in the Metsä Board Husum mill (Husum, Sweden). The ScanChip analyzer is an automatized system for online analysis of wood chips on the basis of three-dimensional laser scanning. The samples were inserted manually into the analyzer.

\section{Results and discussion}

\section{Materials and methods}

Wood chippers: The demonstration-scale drum chipper, which was constructed by Multi Channel Sweden AB (Bredbyn, Sweden), had a drum diameter of $4 \mathrm{~m}$, a width of $1 \mathrm{~m}$, and was equipped with 24 knives. The conventional disc chipper used for comparison was a production chipper at a kraft pulp mill in southern Scandinavia. The chippers were evaluated during production of kraft pulp. The chipping speed varied between 28 and $36 \mathrm{~m} / \mathrm{s}$ depending on the production rate. For both chippers, standard cutting angles were used (i.e. $\varepsilon$ was slightly above $30^{\circ}$ ).

Sampling of wood chips: Wood chips were produced from debarked wood logs of a softwood industrial mix of Norway spruce [Picea abies (L). H. Karst] and Scots pine (Pinus sylvestris L.) at the wood yard of the kraft pulp mill. The fraction of accept chips could potentially differ between samples taken from the same chipper as the result of feedstock differences and the wear of the knife. Feedstock differences include differences related to moisture content, tree age, and log size. Wood chips were collected during the summer season (in June) during normal pulp production, which means

\section{Bulk density}

Table 1 shows the analysis of bulk density. There was no significant $(\mathrm{P}>0.05$, t-test) difference in bulk density between wood chips from the drum chipper and the disc chipper at the kraft pulp mill (Table 1). For wood chips from both the disc chipper and the drum chipper, the bulk density values were around $140 \mathrm{~kg} / \mathrm{m}^{3}$, which is close to the values for softwood as described in the SCAN-CM 46:92 method $\left(153-157 \mathrm{~kg} / \mathrm{m}^{3}\right)$. Differences in bulk density between different studies can, for example, depend on differences in wood chip dimensions and shape, differences between wood species, and moisture content (Edberg et al. 1973). The fact that the drum chipper provided wood chips with similar bulk density as the disc chipper indicates that the new wood chipper construction is not associated with problems caused by excessive curling of wood chips. 
Table 1: Bulk density determined using SCAN-CM 46:92 and average values from size-distribution determination using SCAN-CM 40:01 or ScanChip analyzer.

\begin{tabular}{|c|c|c|c|c|c|c|}
\hline \multirow[b]{2}{*}{ Parameter/fraction } & \multirow[b]{2}{*}{ Definition $^{a}$} & \multicolumn{2}{|r|}{ SCAN } & \multicolumn{3}{|c|}{ ScanChip } \\
\hline & & Disc chipper & Drum chipper & Disc chipper & Drum chipper & Significance $^{b}$ \\
\hline Bulk density $\left(\mathrm{kg} / \mathrm{m}^{3}\right)$ & - & $138 \pm 6$ & $140 \pm 4$ & - & - & No \\
\hline Oversized chips (\%) & $>\varnothing 45$ & $2.4 \pm 1.5$ & $2.6 \pm 1.1$ & $0.2 \pm 0.4$ & $1.4 \pm 0.7$ & $\mathrm{No}^{\mathrm{c}} / \mathrm{yes}^{\mathrm{c}}$ \\
\hline Overthick chips (\%) & $>/ / 8$ & $8.9 \pm 1.6$ & $8.7 \pm 1.5$ & $8.6 \pm 2.3$ & $9.4 \pm 1.9$ & No \\
\hline Large accept chips (\%) & $>\varnothing 13$ & $48.7 \pm 5.4$ & $73.7 \pm 2.6$ & $48.4 \pm 5.0$ & $74.4 \pm 2.3$ & Yes \\
\hline Small accept chips (\%) & $>\varnothing 7$ & $28.0 \pm 4.4$ & $11.7 \pm 1.8$ & $27.5 \pm 2.8$ & $11.6 \pm 1.0$ & Yes \\
\hline Pin chips (\%) & $>\emptyset_{3}$ & $10.7 \pm 2.7$ & $2.7 \pm 0.6$ & $13.0 \pm 3.4$ & $2.9 \pm 0.4$ & Yes \\
\hline Fines (\%) & $<\varnothing_{3}$ & $1.4 \pm 0.5$ & $0.5 \pm 0.1$ & $2.4 \pm 1.0$ & $0.3 \pm 0.1$ & Yes \\
\hline Total accept ${ }^{d}(\%)$ & - & $76.7 \pm 2.2$ & $85.4 \pm 1.5$ & $75.9 \pm 3.3$ & $85.9 \pm 2.2$ & Yes \\
\hline
\end{tabular}

a $\emptyset$, screen hole diameter in $\mathrm{mm}$; //, screen slot distance in $\mathrm{mm}$ or diameter calculated using the ScanChip program.

bDifference between the disc chipper and the drum chipper (t-test): $n o=P>0.05$, yes $=P \leq 0.01$.

"No" refers to the SCAN method, and "yes" refers to the ScanChip method.

dSum of large and small accept chips.

\section{Size-distribution determination using standard methods}

The size distribution as determined using the standard method based on screening is shown in Table 1. The combined fractions of oversized and overthick chips were $11.3 \%$ for both the disc chipper and the drum chipper (Table 1), and no significant $(\mathrm{P}>0.05$, t-test) differences were observed for these two fractions. The drum chipper produced a very large fraction of large accept chips $(73.7 \%)$, significantly larger $(\mathrm{P} \leq 0.01)$ than that of the disc chipper (48.7\%) (Table 1). Although the fraction of small accept chips was larger for the disc chipper than for the drum chipper, the combined fraction of large and small accept chips was significantly $(\mathrm{P} \leq 0.01)$ larger for the drum chipper (85.4\%) compared to the disc chipper (76.7\%). Compared to the disc chipper, the drum chipper generated 51\% more large accept chips and $11 \%$ more total accept chips. The fractions of pin chips and fines were significantly $(\mathrm{P} \leq 0.01)$ smaller for the drum chipper than for the disc chipper (Table 1). The combined fraction of pin chips and fines was $12.1 \%$ for the disc chipper compared to only $3.2 \%$ for the drum chipper. Thus, the drum chipper generated $74 \%$ less pin chips and fines than the disc chipper.

For an industrial-sized chipper fed with mixed raw material, an accept fraction of over $85 \%$, as for the drum chipper (Table 1), is a satisfactory result. For continuous digesters, Hartler (1996) considered $8-11 \%$ as the acceptable upper level for the combined fraction of pin chips and fines. The fraction of pin chips and fines from the disc chipper was above this level, whereas the drum chipper provided a value far below the limit, even without screening.

\section{Size distribution using image analysis}

The wood chip samples were also characterized using a ScanChip analyzer. The ranges and the median values for thickness, length, and width are shown in Figure 3. For both chippers, the largest fraction of wood chips had a median thickness of $7 \mathrm{~mm}$ (Figure 3a). The thickness of the chips from the disc and the drum chippers was rather similar, although the fraction of thinner wood chips $(\leq 6 \mathrm{~mm})$ was slightly higher for the drum chipper. In agreement with that, the fraction of thicker wood chips ( $\geq 8 \mathrm{~mm}$ ) was slightly higher for the disc chipper (Figure 3a). The average thickness of the wood chips was $4.6 \pm 0.3 \mathrm{~mm}$ for the disc chipper and $4.3 \pm 0.1 \mathrm{~mm}$ for the drum chipper.

The thickness of the wood chips is important for alkaline impregnation. Changes in thickness will affect processability and can give larger amounts of shives. Overthick wood chips are associated with poor pulp quality (Hartler 1996). Increased mean thickness has been found to result in less uniform kappa number distribution affecting the formation of reject and delignification (Dang and Nguyen 2008). Thus, it is advantageous to have a low fraction of overthick wood chips, as was achieved with the drum chipper.

The average length was $22.4 \pm 1.2 \mathrm{~mm}$ for the disc chipper and $23.3 \pm 0.4 \mathrm{~mm}$ for the drum chipper. The length of the wood chips was more homogenous for the drum chipper than for the disc chipper (Figure 3b). 
a

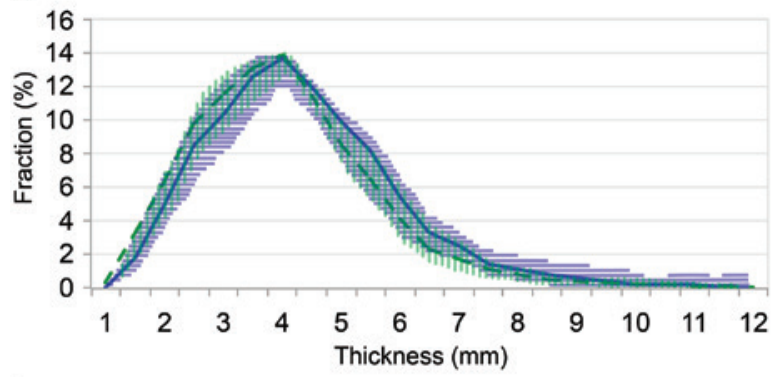

b

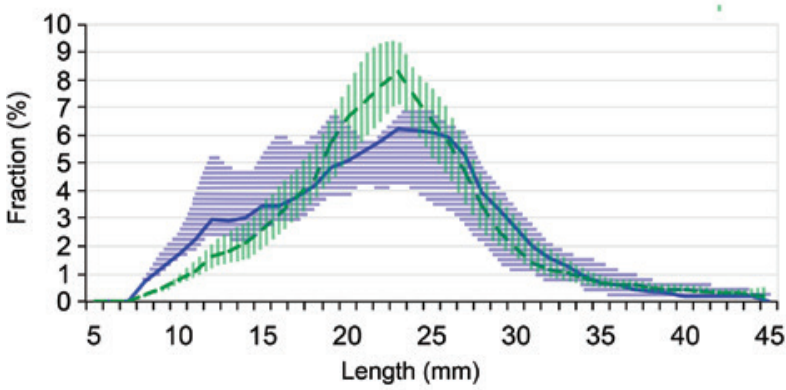

c

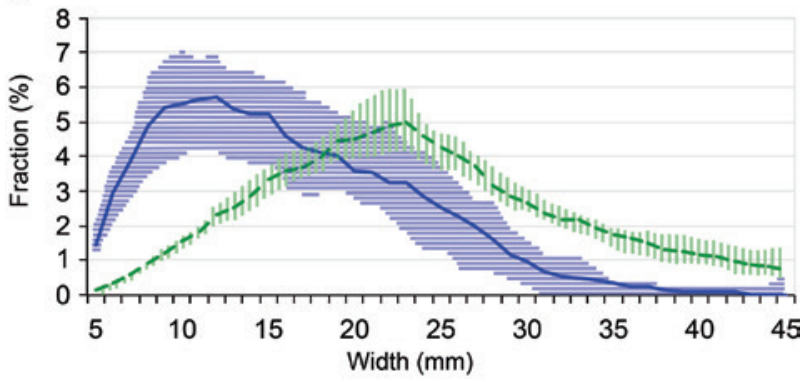

Figure 3: Analysis of size distribution using the ScanChip analyzer. Fractions of wood chips as a function of (a) thickness, (b) length, and (c) width according to measurements using the ScanChip analyzer. The figure shows median values for wood chips from the demonstration drum chipper (dashed green line) and the conventional industrial disc chipper (solid blue line). Green-shaded and blue-shaded areas indicate the size range (thickness, length, or width) of the wood chips from the demonstration drum chipper and the conventional industrial disc chipper, respectively.

The fraction of wood chips with the most common median length, $23 \mathrm{~mm}$, was $6.2 \%$ for the disc chipper and $8.3 \%$ for the drum chipper (Figure $3 b)$.

Too short chip length can give a weaker pulp. Therefore, it is important for making a meaningful comparison that the average length of the wood chips from the disc and the drum chippers was similar.

The average width after chipping was $16.7 \pm 1.1 \mathrm{~mm}$ for the disc chipper and $24.3 \pm 2.4 \mathrm{~mm}$ for the drum chipper. The most common width fraction after chipping was $12 \mathrm{~mm}$ for the disc chipper and $23 \mathrm{~mm}$ for the drum chipper (Figure 3c). However, the width could be affected by the handling of the wood chips before they enter the digester. The average width before the digester was $17.1 \pm 0.4 \mathrm{~mm}$ for the disc chipper and $22.5 \pm 0.6 \mathrm{~mm}$ for the drum chipper. Thus, the difference in width decreased before the digester.

The width is typically not considered critical for the pulping process in the same way as the thickness and the length (Abdallah et al. 2011). However, the width can potentially affect the bulk density (Edberg et al. 1973), which in turn can affect the inflow of wood to the digester or refiner. In this case, the bulk density measurements (Table 1) did not show any difference, and the increase in width observed for wood chips from the drum chipper had no noticeable effect on the kraft pulping process.

The fractions of wood chips of different dimensions, as determined for wood chips from both the drum chipper and the disc chipper by analysis using the ScanChip analyzer, are shown in Figure 4. As for the analysis using the SCAN method, the fractions of oversized and overthick chips from the disc and the drum chippers were similar (Figure 4). Oversized wood chips can be formed when small logs get into the chipper crosswise and are disintegrated into splinters. For both the drum chipper and the disc chipper, the fractions of oversized wood chips were smaller in the analysis using the ScanChip analyzer $(\leq 1.4 \%)$ than using the SCAN method (2.4-2.6\%) (Table 1). The difference can be due to the fact that the ScanChip selectively analyzes fragments that have dimensions akin to regular wood chips, whereas the SCAN method would also cover fragments that have unusual dimensions.

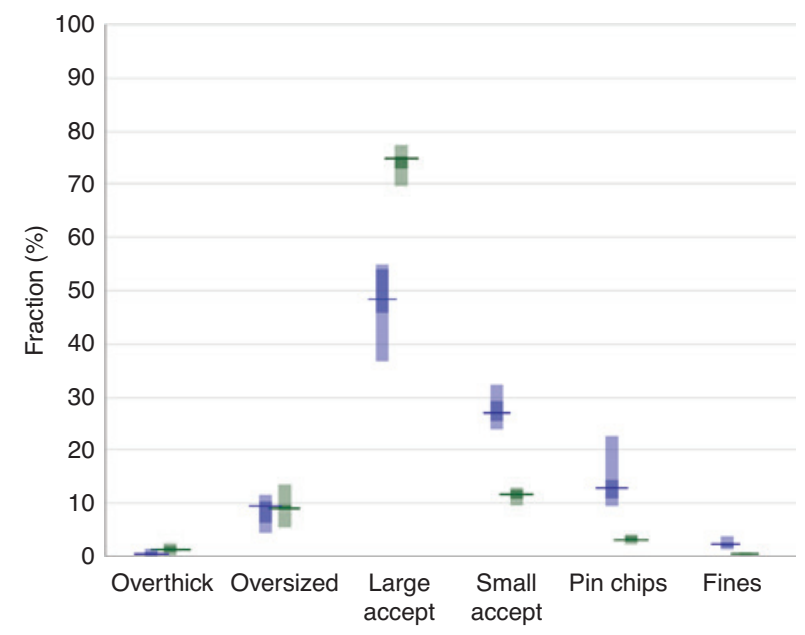

Figure 4: Fractions of wood chip dimensions according to the ScanChip analyzer.

The solid lines show median values for wood chips from the demonstration drum chipper (green) and the conventional industrial disc chipper (blue). Shaded areas indicate size ranges. Darker shades indicate ranges from the first to the third quartiles. 
The fraction of large accept chips was larger for the drum chipper, whereas the fraction of small accept chips was larger for the disc chipper (Figure 4). When the large and small accept chips were combined into a total accept fraction, the average values were $75.9 \pm 3.3 \%$ for the disc chipper and $85.9 \pm 2.2 \%$ for the drum chipper. In agreement with the values obtained using the SCAN method, the fractions of pin chips and fines were much smaller for the drum chipper (Figure 4). The average values for the fractions of pin chips were $13.0 \pm 3.4 \%$ for the disc chipper and $2.9 \pm 0.4$ for the drum chipper (Table 1). For fines, the corresponding values were $2.4 \pm 1.0 \%$ for the disc chipper and $0.3 \pm 0.1 \%$ for the drum chipper (Table 1). When pin chips and fines were combined, the fractions were $15.3 \pm 4.1 \%$ for the disc chipper and $3.3 \pm 0.5 \%$ for the drum chipper. Thus, image analysis indicated that the drum chipper generated $78 \%$ less pin chips and fines than the disc chipper.

Analyses of thickness (Figure 3a), length (Figure 3b), and fraction sizes (Figure 4) indicate that the wood chips from the drum chipper were more uniform in size than the wood chips from the disc chipper. A more uniform thickness and size can give higher pulp quality with a lower reject fraction and more pulp from a given amount of raw material. Fractions of too small particles, i.e. pin chips and fines, are, at least in part, removed by screening and used for production of heat. Therefore, lower fractions of pin chips and fines will also increase the amount of produced pulp from a given amount of raw material. Although some part of the fractions with small particles will still go into the digester, pulp produced from fines has low quality and fines can also affect the flow of black liquor in the digester. Thus, decreasing the smaller fractions will save raw material and energy, improve processability, and improve the economy of the mill.

\section{Impact of chipper design}

The goal of this study was to investigate wood chips produced with a novel type of drum chipper and compare them with conventional wood chips from an industrial disc chipper. The better uniformity of the wood chips observed with the new drum chipper can be attributed to the even velocity of the knives and/or to the less variable wood chipping angles, for example, the sharpness angle. The knives of the conventional disc chipper were changed 3 times a week. With regard to the new drum chipper, it was sufficient to change the knives once a week. These differences could be attributed to the more even velocity of the knives of the drum chipper, and by less wear on the knives. As there would be less force on the knives of the drum chipper than on the knives of the disc chipper, there may be small differences in sharpness angle. Less forceful wood chipping could also explain the increased width of the wood chips from the drum chipper. The use of less force for the wood chipping could also affect both the tendency to form cracks and the energy demand, which need to be further investigated in the future.

\section{Conclusions}

The comparison of wood chips from a conventional kraft mill disc chipper and a newly constructed drum chipper showed that the wood chips from the drum chipper had several advantages, such as a more uniform size distribution with maintained average thickness and length, larger fractions of accept chips, and smaller fractions of pin chips and fines.

The wood chips from the drum chipper had a larger width, but this did not seem to have any negative consequences, and, importantly, the wood chips produced with the drum chipper had similar bulk density as the wood chips from the disc chipper. Potential savings with regard to feedstock demand, improved yield of high-quality pulp, and lower energy demand warrant further attention in future studies. The possibility to utilize the new chipping technology to produce thinner wood chips without a concomitant decrease in the fraction of accept chips would need to be addressed in future studies. Furthermore, it would also be of interest to study the new drum chipping technology with regard to wood chips for acidic pulping processes, where the impregnation step differs considerably compared to that of alkaline pulping processes.

Acknowledgments: We thank Sten Häggström (Multi Channel Sweden $A B$ ) for help with sampling of wood chips, and Metsä Board Husum (Husum, Sweden) for providing access to their ScanChip analyzer.

Author contributions: All the authors have accepted responsibility for the entire content of this submitted manuscript and approved submission.

Research funding: The support provided by the Swedish Energy Agency, Funder Id: http://dx.doi. org/10.13039/501100004527 (P40512-1), the Kempe Foundations, the Umeå University Industrial Doctoral School, RISE Processum, and Bio4Energy (www.bio4energy.se) is gratefully acknowledged. 
Employment or leadership: None declared.

Honorarium: None declared.

\section{References}

Abdallah, R., Auchet, S., Méausoone, P.J. (2011) Experimental study about the effects of disc chipper settings on the distribution of wood chip size. Biomass Bioenerg. 35:843-852.

Brännvall, E. (2009) Wood handling. In: Pulping Chemistry and Technology. Eds. Ek, M., Gellerstedt, G., Henriksson, G. De Gruyter, Berlin, pp. 13-34.

Brännvall, E., Bäckström, M. (2016) Improved impregnation efficiency and pulp yield of softwood kraft pulp by high effective alkali charge in the impregnation stage. Holzforschung 70:1031-1037.

Brännvall, E., Reimann, A. (2018) The balance between alkali diffusion and alkali consuming reactions during impregnation of softwood. Impregnation for kraft pulping revisited. Holzforschung 72:169-178

Dang, V.Q., Nguyen, K.L. (2008) A universal kinetic model for characterisation of the effect of chip thickness on kraft pulping. Bioresour. Technol. 99:1486-1490.

Edberg, U., Engström, L., Hartler, N. (1973) The influence of chip dimensions on chip bulk density. Svensk Papperstidn. 14:529-533.

Hartler, N. (1962) The effect of spout angle as studied in an experimental chipper. Svensk Papperstidn. 65:351-362.

Hartler, N. (1996) Achievement and significance of optimal chip quality. TAPPI J. 79:259-264.

Hartler, N., Stade, Y. (1977) Chipper operation for improved chip quality. Svensk Papperstidn. 80:447-453.
Hellström, L., Gradin, P., Engstrand, P., Gregersen, Ø. (2011) Properties of wood chips for thermomechanical pulp (TMP) production as a function of spout angle. Holzforschung 65:805-805.

Määttänen, M., Tikka, P. (2008) Penetration of water and black liquor into overthick and treated wood chips. Pap. Puu-Pap. Tim. 90:34-39.

Malkov, S., Tikka, P., Gullichsen, J. (2002) Towards complete impregnation of wood chips with aqueous solutions. Part 4: effects of front-end modifications in displacement batch kraft pulping. Pap. Puu-Pap. Tim. 84:526-530.

Malkov, S., Tikka, P., Gustafson, R., Nuopponen, M., Vourinen, T. (2003) Towards complete impregnation of wood chips with aqueous solutions. Part 5: improving uniformity of kraft displacement batch pulping. Pap. Puu-Pap. Tim. 85:215-220.

Nati, C., Eliasson, L., Spinelli, R. (2014) Effect of chipper type, biomass type and blade wear on productivity, fuel consumption and product quality. Croat. J. For. Eng. 35:1-7.

Pichler, P., Leitner, M., Grün, F., Guster, C. (2018) Experimental determination of highly dynamic forces during wood trunk comminution with a drum chipper. J. Agric. Eng. 49:110-116.

Rydholm, S.A. Pulping Processes. Robert E. Krieger Publishing, Malabar, FL, 1965, pp. 263-274, 294.

Tavast, D., Brännvall, E. (2017) Increased pulp yield by prolonged impregnation in softwood kraft pulping. Nord. Pulp Pap. Res. J. 32:14-20.

Twaddle, A. (1997) The influence of species, chip length, and ring orientation on chip thickness. TAPPI J. 80:123-131.

Uhmeier, A. (1995) Some fundamental aspects of wood chipping. TAPPI J. 78:79-86.

Wedin, H., Lindström, M.E., Ragnar, M. (2010) Extended impregnation in the kraft cook - an approach to improve the overall yield in eucalypt kraft pulping. Nord. Pulp Pap. Res. J. 25:7-14. 